\title{
Tailoring the band gap in the ZnS-ZnSe system: Solid solutions by mechanically induced self-sustaining reaction
}

\author{
Miguel A. Avilés ${ }^{\dagger}$, José M. Córdoba ${ }^{\dagger \ddagger}$, María J. Sayagués ${ }^{\dagger}$, and Francisco J. Gotor ${ }^{*}$ \\ † Instituto de Ciencia de Materiales de Sevilla (US-CSIC), 41092 Sevilla, Spain \\ ‡ Departamento de Química Inorgánica, Universidad de Sevilla, 41012 Sevilla, Spain
}

\begin{abstract}
The complete $\mathrm{ZnS}_{\mathrm{x}} \mathrm{Se}_{1-\mathrm{x}}$ solid solution was successfully obtained by the mechanochemical process denoted as mechanically-induced self-sustaining reaction (MSR). An excellent control of the chemical stoichiometry of the solid solution was possible by adjusting the atomic ratio of the starting $\mathrm{Zn} / \mathrm{S} / \mathrm{Se}$ elemental mixture subjected to milling. A mixture of both wurtzite-2H (hexagonal) and zinc blende (cubic) structures was always obtained, although for a similar milling time the proportion of the zinc blende structure increased with the Se content in the solid solution. However, wurtzite was the major phase for S-rich compositions when milling was stopped just after ignition. It was demonstrated that milling induces the wurtzite-to-zinc blende phase transition. The $8 H$ hexagonal polytype was also observed in samples subjected to long milling times. The variation of the lattice parameters for both structures with the $x$ value in the solid solution presented an excellent linearity, confirming the validity of the Vegard's law. However, the variation of the band gap energy $\left(\mathrm{E}_{\mathrm{g}}\right)$ with $x$ was not perfectly linear and a small bowing parameter of 0.34 was obtained. It was possible to tune the $\mathrm{E}_{\mathrm{g}}$ value between those of the end members of the solid solution in a continuous manner by adjusting the stoichiometry of the solid solution. The morphology and the crystalline domain size can be also controlled by adjusting, in this case, the post-ignition milling time of the mechanochemical process.
\end{abstract}

KEYWORDS: Mechanochemistry, Combustion process, Semiconductor, Optical properties

\section{INTRODUCTION}

Zinc sulfide $(\mathrm{ZnS})$ and zinc selenide (ZnSe) are IIVI semiconductor materials with wide direct band gap that attract much attention due to a great variety of electronic and optoelectronic applications, including light emitting diodes, electroluminescence, lasers, flat panel displays, infrared windows and sensors, among others ${ }^{1-2}$. ZnS presents two stable polymorphs at atmospheric pressure, the cubic zinc blende or sphalerite (F-43m) and the hexagonal wurtzite- $2 \mathrm{H}$ $\left(\mathrm{P}_{3} \mathrm{mc}\right)$, being the sphalerite phase thermodynamically stable below $1293 \mathrm{~K}$. A cubic rock salt structure (Fm-3m) has also been reported, but this phase can only be obtained under high pressure conditions ${ }^{3,4}$. Although, most synthesis methods yield $\mathrm{ZnS}$ with the sphalerite structure, the synthesis of $\mathrm{ZnS}$ with wurtzite structure using mild- or low-temperature processes has also been reported ${ }^{5-7}$. It has been shown that the formation of a nanometric microstructure and the control of the particle morphology can favor the formation of the wurtzite structure ${ }^{8,9}$. ZnSe presents only one thermodynamically stable phase under normal pressure, the stilleite with zinc blende structure. Although the predicted temperature for the zinc blende-to-wurtzite phase transition in $\mathrm{ZnSe}$ is above its melting point ${ }^{10}$, examples in which the wurtzite structure was obtained using similar methods as for $\mathrm{ZnS}$ can also be found in the literature ${ }^{11-13}$. This is related to a small energy difference between the two structures ${ }^{14}$. A high-pressure cubic structure has also been reported for $\mathrm{ZnSe}^{15}$.

The band gap energy $\left(\mathrm{E}_{\mathrm{g}}\right)$ of $\mathrm{ZnS}$ is 3.6 and $3.8 \mathrm{eV}$ for the zinc blende and wurtzite structures, respectively, and $2.58 \mathrm{eV}$ for $\mathrm{ZnSe}$ with zinc blende structure $^{16}$. Since $\mathrm{ZnS}$ and $\mathrm{ZnSe}$ have identical crystal structures and small lattice parameter mismatch, they can form a solid solution $\left(\mathrm{ZnS}_{\mathrm{x}} \mathrm{Se}_{1-\mathrm{x}}\right)$ over the whole compositional range. This solid solution provides the possibility of tuning $\mathrm{E}_{\mathrm{g}}$ and facilitate optical and elec- 
tronic engineering by controlling the chemical composition $^{17}$. It has been shown in $\mathrm{ZnS}_{\mathrm{x}} \mathrm{Se}_{1-\mathrm{x}}$ with zinc blende or wurtzite structure that $\mathrm{E}_{\mathrm{g}}$ varies gradually with the chemical composition ${ }^{18-31}$. Although lattice parameter in $\mathrm{ZnS}_{\mathrm{x}} \mathrm{Se}_{1-\mathrm{x}}$ nearly follows the Vegard's $\operatorname{law}^{18,19,21,24,28}$, it has been frequently observed that the dependence of $E_{g}$ with the stoichiometry of the solid solution is not strictly linear ${ }^{19-23,25-31}$. A quadratic function expresses this dependence more precisely with a bowing parameter, $b$, in the $0.35^{-0.68 ~ e V ~ r a n g e ~} \mathrm{eV}^{19-23,26-}$ 29. However, few authors have shown a linear relationship with the composition ${ }^{24,31}$. The $\mathrm{ZnS}_{\mathrm{x}} \mathrm{Se}_{1-\mathrm{x}}$ solid solution has been generally synthesized by different thermal evaporation processes ${ }^{21-24,26-30}$. In some cases, the authors state that the solid solution was obtained with the zinc blende structure and in other cases with the wurtzite structure; however, a careful observation of results shown, especially the X-ray diffraction (XRD) diagrams, suggests that in many cases a mixture of both structures was in fact obtained ${ }^{24,26,27,29,30}$.

Mechanochemical synthesis procedures are generally performed in high-energy ball-milling equipment, in which solid state reactions are induced by applying mechanical energy to a reactant mixture ${ }^{32}$. It has been reported that $\mathrm{ZnS}$ and $\mathrm{ZnSe}$ can be obtained by milling their respective $\mathrm{Zn}-\mathrm{S}$ and $\mathrm{Zn}$-Se elemental mixtures $33^{-45}$, although other mechanochemical processes based on displacement reactions have also been informed ${ }^{46-48}$. The reactions of formation of $\mathrm{ZnS}$ and $\mathrm{ZnSe}$ are highly exothermic 49 and fulfil the empirical Merzhanov's criterion for combustion processes (adiabatic temperature $\left(\mathrm{T}_{\mathrm{ad}}\right)>1800 \mathrm{~K}$ ). If the required energy to ignite a self-propagating reaction is provided by mechanical energy, not by heat as in the self-propagating high-temperature synthesis (SHS) process, the method is referred to as a mechanically induced self-sustaining reaction (MSR). In MSR, ignition occurs after a critical milling time called the ignition time $\left(t_{\mathrm{ig}}\right)$, which depends on the reactant system and the milling conditions ${ }^{50-52}$. The occurrence of an MSR process during milling $\mathrm{Zn}-\mathrm{S}$ or $\mathrm{Zn}-\mathrm{Se}$ mixtures has been reported in several works 33-35,43,44. However, in other studies, the MSR effect has not been outlined ${ }^{36-42,45}$, although it cannot be excluded as the products were generally inspected after long milling times, after ignition was likely to have occurred. The formed $\mathrm{ZnS}$ or $\mathrm{ZnSe}$ is mainly obtained with the zinc blende structure, although the wurtzite phase and even a mixture of both phases has also been reported. The different milling times employed in the different studies, which extend from a few minutes to tens of hours, can be at the origin of these contradictory results concerning the resulted structure, since it has also been shown the occurrence of phase transformation phenomena driven by highenergy ball-milling. Unfortunately, there are also contradictory results in this issue. Whereas some authors have shown that milling induces the wurtzite-to-zinc blende phase transition in $\mathrm{ZnS}$ and $\mathrm{ZnSe}^{41,53}$, other authors have shown the opposite effect, that milling promotes the zinc blende-towurtzite phase transformation in $\mathrm{ZnS} 54$.

In this work, the synthesis by MSR of the complete solid solution in the ZnS-ZnSe system was performed. MSR is a dry, time saving and waste-free method, which could be interesting for a subsequent semiconductor technology. The main goal of this study was to present an easy and adequate synthesis method that allows the tailoring of $\mathrm{E}_{\mathrm{g}}$ by controlling the stoichiometry of the $\mathrm{ZnS}_{\mathrm{x}} \mathrm{Se}_{1-\mathrm{x}}$ series. Moreover, we clarified the contradictory results found in the bibliography on which phases, the zinc blende or wurtzite, are obtained from mechanochemical processes. The quantification of both phases as a function of the chemical composition and the milling time after ignition was studied, always taking into account the possible changes in $\mathrm{E}_{\mathrm{g}}$.

\section{EXPERIMENTAL SECTION}

Zinc powder (99\% pure, < 325 mesh, Strem Chemicals), sulfur powder (99.5\% pure, < 325 mesh, Alfa Aesar), selenium powder (99.5\% pure, < 325 mesh, Alfa Aesar) and high-purity argon gas $\left(\mathrm{H}_{2} \mathrm{O}\right.$ and $\mathrm{O}_{2}<$ 3 ppm, Linde) were used in this work for the synthesis of $\mathrm{ZnS}_{\mathrm{x}} \mathrm{Se}_{1-\mathrm{x}}$ solid solution by an MSR process using a modified planetary ball mill (Micro Mill Pulverisette 7, Fritsch). All of the milling experiments were conducted under an Ar atmosphere (6 bar) using $3 \mathrm{~g}$ of $\mathrm{Zn} / \mathrm{S} / \mathrm{Se}$ elemental mixtures with different atomic ratios according to the $\mathrm{ZnS}_{\mathrm{x}} \mathrm{Se}_{1-\mathrm{x}}$ stoichiometry intended. Six AISI $420 \mathrm{C}$ stainless steel balls $(\mathrm{d}=15 \mathrm{~mm}$ and $\mathrm{m}=13.7 \mathrm{~g}$ ), a $60 \mathrm{~mL}$ tempered steel vial (inner diameter $=45 \mathrm{~mm}$ ) and a rotational speed of the supporting disk of $400 \mathrm{rpm}$ were employed. Detection during milling of $t_{i g}$ in MSR process was possible since the vial with a special lid was continuously connected to the gas cylinder by a rotating union (model 1005-163-038, Deublin) and a semi-rigid polyamide tube (Legris), and the Ar pressure was monitored by a pressure transducer (AKS, Danfoss) connected to a paperless recorder (Ecograph T RSG35, Endress + Hauser). At ignition, the heat released by the exothermic reaction of the $\mathrm{ZnS}_{\mathrm{x}} \mathrm{Se}_{1-\mathrm{x}}$ formation provoked an instantaneous increase in the total pressure of the system that resulted in the appearance of a peak in the pressure-time record, from which $t_{i g}$ was obtained. 


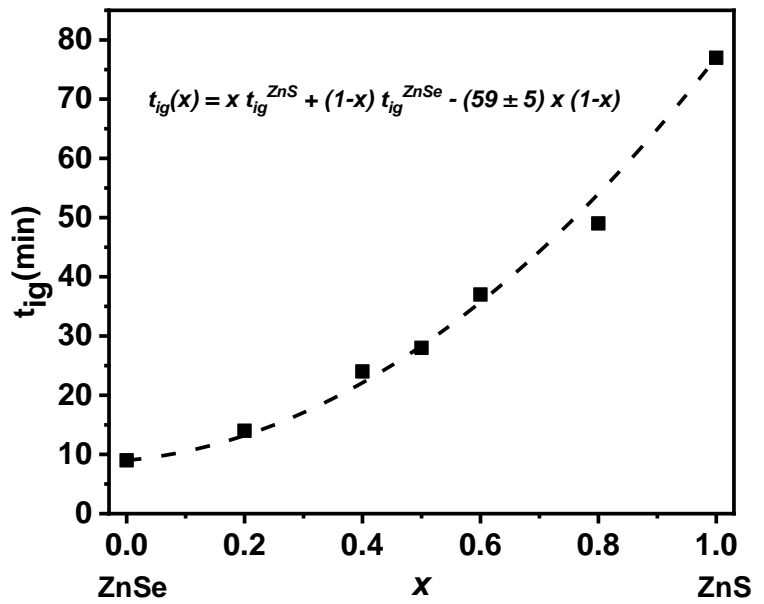

Figure 1. Ignition time $\left(t_{\mathrm{ig}}\right)$ of the MSR process involving the milling of different $\mathrm{Zn} / \mathrm{S} / \mathrm{Se}$ elemental mixtures to obtain the $\mathrm{ZnS}_{\mathrm{x}} \mathrm{Se}_{1-\mathrm{x}}$ solid solution. The $x$ value corresponds to the $[\mathrm{S} /(\mathrm{S}+\mathrm{Se})]$ atomic ratio in the starting mixture.

XRD patterns of milled powders were obtained on a X'Pert Pro MPD diffractometer (PANalytical) equipped with a $\theta / \theta$ goniometer, a graphite-diffracted beam monochromator and a solid-state detector (X'Cellerator). The diffraction patterns were acquired using $\mathrm{Cu} \mathrm{K} \alpha$ radiation over a $2 \theta$-range of $10^{\circ}$ to $140^{\circ}$ with a step size of $0.033^{\circ}$ and a counting time of 800 s/step. Silicon powder (Standard Reference Material 640c, NIST) was used for calibration of the diffraction line positions. The quantification of phases detected in the XRD patterns was performed by means of the Rietveld method using the FULLPROF program 55 . A Thompson-Cox-Hastings pseudo-Voigt function convoluted with an axial divergence asymmetry function was chosen to generate the peak shapes. The following parameters were refined: background points, zero point, scale factor, pseudo-Voigt parameters of the peak shape and cell parameters. The following reference diffraction patterns from the PDF-4 + database of the International Centre for Diffraction Data (ICDD) were used as the initial model: $\mathrm{ZnS}(\mathrm{F}-43 \mathrm{~m}$, a $=\mathrm{b}=\mathrm{c}=5.4060 \AA \AA 05$; 05-0566), ZnSe (F-43m, a = b = c = 5.6688 Аं; 37-1463), ZnS (P6 ${ }_{3} \mathrm{mc}, \mathrm{a}=\mathrm{b}=3.8210, \mathrm{c}$ $=6.2573 \AA$; $36-1450)$ and ZnSe $\left(\mathrm{P} 6_{3} \mathrm{mc}, \mathrm{a}=\mathrm{b}=3.9960\right.$, c $=6.5500 \AA$ 品 15 -0105).

Powder samples after milling were dispersed in ethanol, and droplets of the suspension were deposited onto a carbon coated copper grid for microscopy analysis. The scanning electron microscopy (SEM) images were obtained on a Hitachi S-48oo SEM-Field Emission Gun microscope. The transmission electron microscopy (TEM) and high resolution (HRTEM) images, electron diffraction patterns (EDP) and energy dispersive X-ray (EDX) spectra were taken on a $200 \mathrm{kV} \mathrm{JEOL-2100-PLUS} \mathrm{microscope} \mathrm{equipped} \mathrm{with} \mathrm{a}$ $\mathrm{LaB}_{6}$ filament (point resolution $=0.25 \mathrm{~nm}$ ). The $\mathrm{HR}$ micrograph analysis, lattice spacing, Fast Fourier Transform (FFT) and phase interpretation were done with the Gatan Digital Micrograph software (Gatan Inc.) and the Java version of the Electron Microscope Software (JEM).

Raman spectroscopy was performed using a dispersive Horiba Jobin Yvon HR8oo confocal Raman Microscope (HORIBA) equipped with a chargecoupled device (CCD) detector at a laser excitation wavelength of $532 \mathrm{~nm}$ (green laser). The spectral resolution was $4 \mathrm{~cm}^{-1}$. The laser beam was focused on the powder samples with a confocal objective of 1oox.

The diffuse reflectance UV-Vis spectroscopy (DRS) of the powder samples was performed using a Cary 300 spectrophotometer from 200 to $800 \mathrm{~nm}$. Eg value was calculated from the corresponding Kubelka-Munk functions, $\mathrm{F}(\mathrm{R} \infty)$, which are proportional to the absorption of radiation, by plotting $(F(R \infty) \times$ $h v)^{1 / 2}$ against $h v$.

\section{RESULTS AND DISCUSSION}

Effects of the $\mathrm{ZnS}_{\mathrm{x}} \mathrm{Se}_{1-\mathrm{x}}$ stoichiometry on the crystal structure and the optical properties.

Seven different $\mathrm{Zn} / \mathrm{S} / \mathrm{Se}$ powder mixtures with stoichiometric atomic ratios according to the $\mathrm{ZnS}_{\mathrm{x}} \mathrm{Se}_{1-}$ $x$ solid solution with $x=1,0.8,0.6,0.5,0.4,0.2$ and o were submitted to milling using the experimental conditions described in the experimental section. For all mixtures, ignition was detected in the timepressure records (a sharp peak appeared) and the corresponding $t_{i g}$ values determined are shown in Figure 1. For this set of samples, milling was prolonged 6o min after ignition. Figure 1 shows as $t_{\text {ig }}$ was gradually shortened as the Se content in the reactant mixture increased. The $t_{\mathrm{ig}}$ variation with the $x$ value, which corresponds to the $[\mathrm{S} /(\mathrm{S}+\mathrm{Se})]$ atomic ratio in the starting $\mathrm{Zn} / \mathrm{S} / \mathrm{Se}$ mixture, was not linear, but a quadratic function defines more precisely this dependence. Note that the standard enthalpy of formation for $\mathrm{ZnS}(-205 \mathrm{~kJ} / \mathrm{mol})$ is greater than for $\mathrm{ZnSe}$ $(-170.3 \mathrm{~kJ} / \mathrm{mol})^{56}$, however, in this case, it follows that the more exothermic reactant mixture, the longer $t_{i g}$. Although one would expect the opposite, more exothermic reactions ignite before, in metal-chalcogen systems, it has been shown that $t_{i g}$ correlates better with the hardness of the reactants; it is shorter for softer metals and harder chalcogens ${ }^{57}$. 

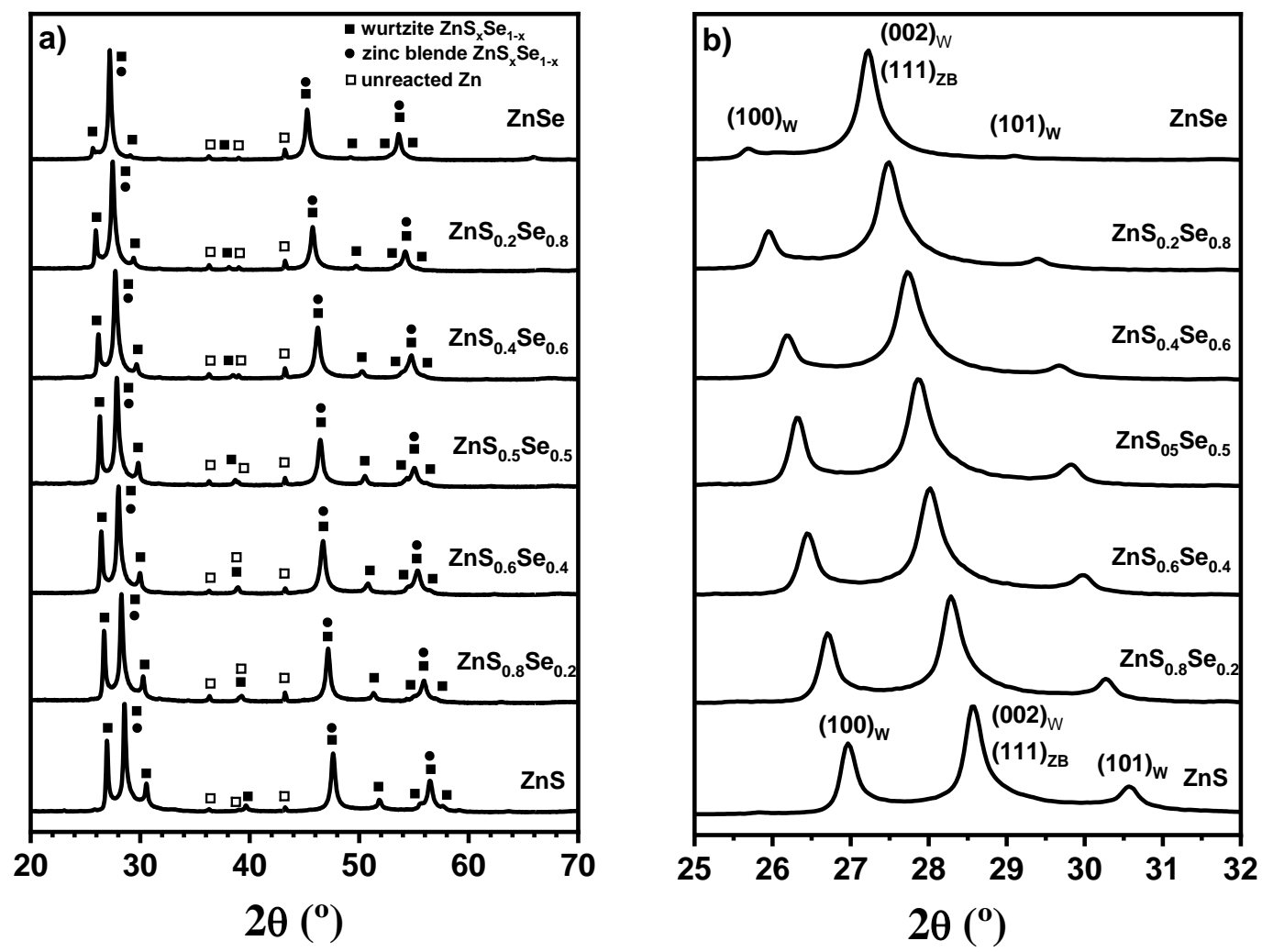

Figure 2. (a) XRD patterns of the different Zn/S/Se mixtures after the MSR process (milling time $=t_{\mathrm{ig}}+60$ min) that show the formation of the $\mathrm{ZnS}_{\mathrm{x}} \mathrm{Se}_{1-\mathrm{x}}$ solid solution. (b) XRD patterns of the same samples in the $25^{0^{-}-32^{\circ}} 2 \theta$ region where the (100), (002) and (101) reflections of the wurtzite phase and the (111) reflection of the zinc blende phase are observed.

Figure 2a presents the XRD patterns of the products after the MSR process that confirmed the formation of the $\mathrm{ZnS}_{\mathrm{x}} \mathrm{Se}_{1-\mathrm{x}}$ solid solution in all cases. The presence of a small amount of unreacted $\mathrm{Zn}$ was also observed. However, no unreacted S and/or Se were noticed, which may be the result of the capacity of high-energy ball milling to induce $\mathrm{S}$ and Se amorphization ${ }^{58,59}$. Figure 2 shows that a mixture of both the zinc blende and wurtzite structures was always obtained after the MSR process and that the proportion of the zinc blende structure increased with the Se content. The existence of both phases was evidenced even in samples with low or no Se content by the relative intensity of the central XRD peak in the triplet appearing in the $25-32^{\circ} 2 \theta$ range (Figure $2 \mathrm{~b}$ ). It is the result of the overlapping of the (111) peak of the zinc blende structure, which is the most intense, with the (002) peak of the wurtzite structure. Note that the most intense XRD peak of the wurtzite structure corresponds to the (100) family planes.

Figure $2 \mathrm{a}$ also shows a clear shift of the XRD peaks of the zinc blende and wurtzite phases to lower angle values as the Se content increased in the starting mixture, which correlates well to an increasingly richer Se stoichiometry in the $\mathrm{ZnS}_{\mathrm{x}} \mathrm{Se}_{1-\mathrm{x}}$ solid solution, leading to an increase in the cell parameters. This is observed more clearly in Figure $2 \mathrm{~b}$, where the $25^{\circ}-32^{\mathrm{o}}$ $2 \theta$ region is enlarged. The broadening and symmetry of the XRD peaks, together with the continuous peak shifting, rule out the possibility of phase separation and suggest the formation of a homogeneous solid solution. To quantify all these different aspects, the Rietveld refinement of the XRD patterns were performed (Figure $\mathrm{S}_{1}$ ), from which the percentage of different phases and the lattice parameters of the solid solution were determined.

The quantification of the zinc blende and wurtzite phases as determined by the Rietveld method is presented in Figure 3 and confirms the presence of both structures in all samples. Note that even the $\mathrm{ZnS}$ sample, with a characteristic XRD pattern similar to others found in the literature, from which the formation of $\mathrm{ZnS}$ with wurtzite structure is frequently established, has a 50 wt.\% content of zinc blende. This amount increases progressively with the Se content in the solid solution. Remember that according 
to the $\mathrm{Zn}$-Se phase diagram ${ }^{10,60}$, the zinc blende structure is the only thermodynamically stable phase up to the melting point of ZnSe. Nevertheless, also for the ZnSe sample, a small amount of the wurtzite phase was observed (11.3 wt.\%). The amount of unreacted $\mathrm{Zn}$ in samples was in the 2.4-3.1 wt.\% range.

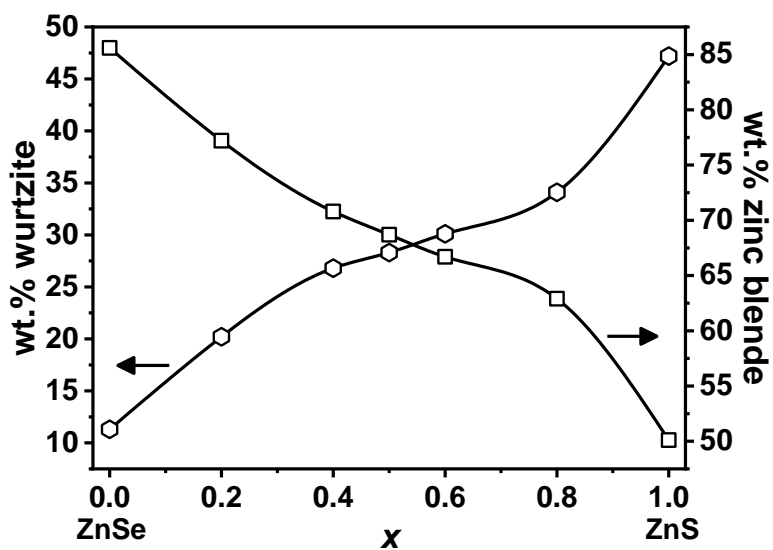

Figure 3. Quantification of the zinc blende and wurtzite phases present in the $\mathrm{ZnS}_{\mathrm{x}} \mathrm{Se}_{1-\mathrm{x}}$ solid solution obtained by MSR by Rietveld refinement of the XRD patterns in Figure 2.

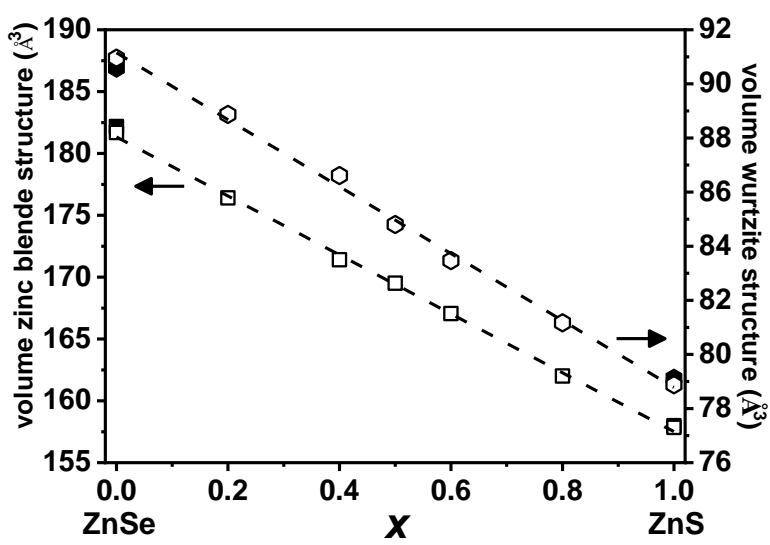

Figure 4. Unit cell volume of the zinc blende and wurtzite structures in the $\mathrm{ZnS}_{\mathrm{x}} \mathrm{Se}_{1-\mathrm{x}}$ solid solution obtained by MSR.

Lattice parameters for the zinc blende and wurtzite structures in the different samples were also refined and the results are shown in Table 1 . The parameters for both structures in $\mathrm{ZnS}$ and $\mathrm{ZnSe}$ samples were in good agreement with those of the reference diffraction patterns of the ICDD database (see the experimental section). As expected, an increasing of the cell parameters with the Se content in the solid solution was observed. Figure 4 presents the variation of the unit cell volume of both structures for the different $\mathrm{ZnS}_{\mathrm{x}} \mathrm{Se}_{1-\mathrm{x}}$ samples. The good linearity observed in both cases with the $x$ value, i.e., the $[S /(S+S e)]$ atomic ratio in the starting $\mathrm{Zn} / \mathrm{S} / \mathrm{Se}$ mixture, confirms the validity of the Vegard's law in the ZnS-ZnSe system, as well as that the composition of the $\mathrm{ZnS}_{\mathrm{x}} \mathrm{Se}_{1-\mathrm{x}}$ solid solution correlates well with the $\mathrm{Zn} / \mathrm{S} / \mathrm{Se}$ atomic ratio in the starting mixture. Figure 4 also points out that for all samples the stoichiometry of the solid solution was the same for both structures formed.

TABLE 1. Lattice parameters of the wurtzite and zinc blende structures present in the $\mathrm{ZnS}_{\mathrm{x}} \mathrm{Se}_{1-\mathrm{x}}$ solid solution obtained by MSR.

\begin{tabular}{cccc} 
& \multicolumn{3}{c}{ Lattice parameters } \\
Sample & \multicolumn{2}{c}{ Wurtzite } & Zinc blende \\
& $a(\AA)$ & $c(\AA)$ & $a(\AA)$ \\
$\mathrm{ZnS}$ & 3.8151 & 6.2577 & 5.4044 \\
$\mathrm{ZnS}_{0.8} \mathrm{Se}_{0.2}$ & 3.8521 & 6.3166 & 5.4513 \\
$\mathrm{ZnS}_{0.6} \mathrm{Se}_{0.4}$ & 3.8884 & 6.3752 & 5.5074 \\
$\mathrm{ZnS}_{0.5} \mathrm{Se}_{0.5}$ & 3.9090 & 6.4081 & 5.5343 \\
$\mathrm{ZnS}_{0.4} \mathrm{Se}_{0.6}$ & 3.9222 & 6.5008 & 5.5548 \\
$\mathrm{ZnS}_{0.2} \mathrm{Se}_{0.8}$ & 3.9615 & 6.5394 & 5.6083 \\
$\mathrm{ZnSe}$ & 4.0002 & 6.5636 & 5.6638
\end{tabular}

Figure 5 exhibits representative microstructural results for selected samples, in particular, for $\mathrm{ZnS}$ (Fig. 5a), $\mathrm{ZnS}_{0.5} \mathrm{Se}_{0.5}$ (Fig. 5b) and ZnSe (Fig. 5c). In the SEM micrographs, it can be seen that the three samples are formed by agglomerated particles, which size ranged between $100 \mathrm{~nm}$ and $1 \mu \mathrm{m}$. The larger particles present platelets shape and the smaller are rounded, that in many cases are deposited on the platelet surface. TEM images show the same type of morphology and the EDPs give information about the crystallinity of the samples. The ring-EDP obtained for the three samples (inset in the TEM images) was the evidence of a nanocrystalline character and, therefore, the particles observed by SEM are in fact constituted by nanocrystalline domains. The $(\mathrm{h}, \mathrm{k}, \mathrm{l})$ planes corresponding to the rings (white marked) were indexed and belong to both crystal symmetry, the zinc blende (cubic, space group F-43m) and the wurtzite (hexagonal $2 \mathrm{H}$, space group P63mc). This information is in good agreement with the XRD results. The nanocrystalline character of the three samples can also be confirmed in the HRTEM micrographs, in which small misoriented nanodomains are observed. Several nanodomains along the [ $\left[\begin{array}{lll}0 & 0 & 1\end{array}\right]$ zone axis of the wurtzite structure are white marked in the HRTEM images and the corresponding FFT and simulated EDP are included as insets. The chemical analysis of the samples was carried out by EDX in both, the SEM and the 
a) $\mathrm{ZnS}$
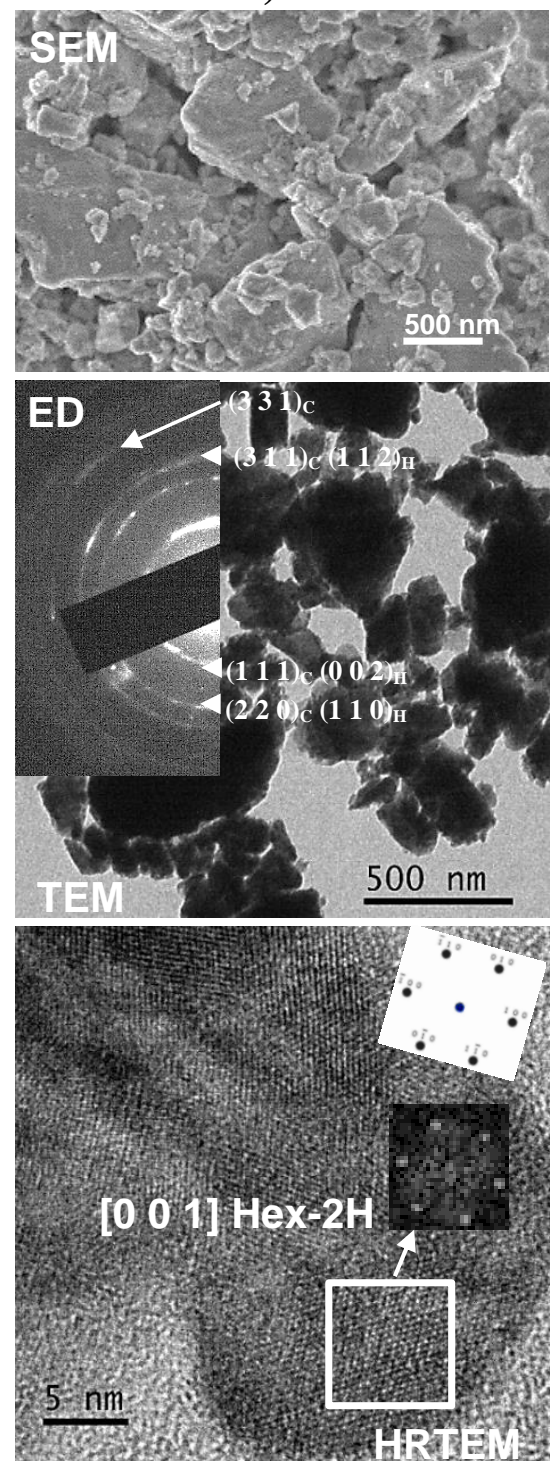

b) $\mathrm{ZnS}_{0.5} \mathrm{Se}_{0.5}$
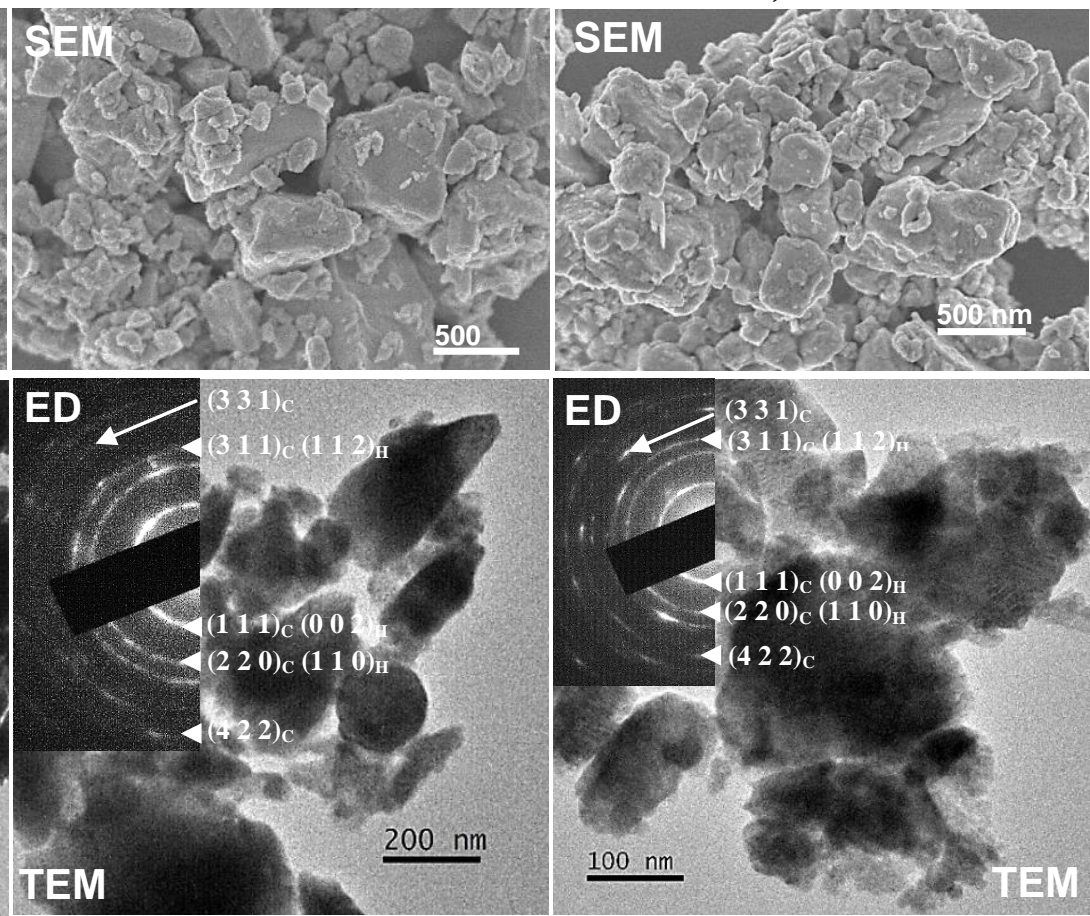

c) $\mathrm{ZnSe}$

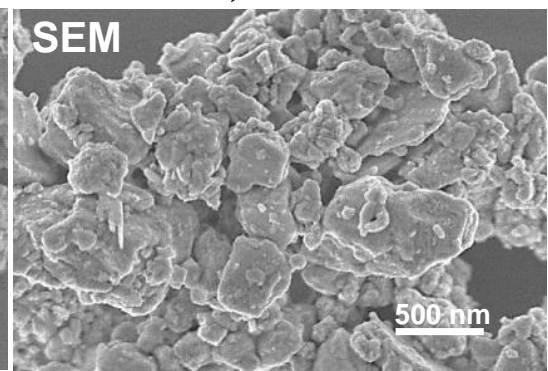

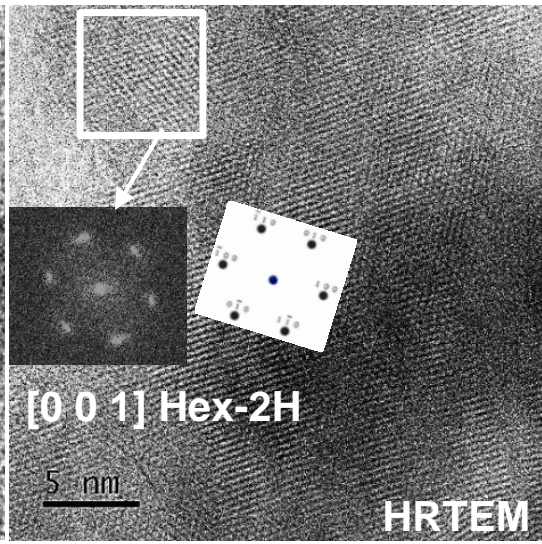
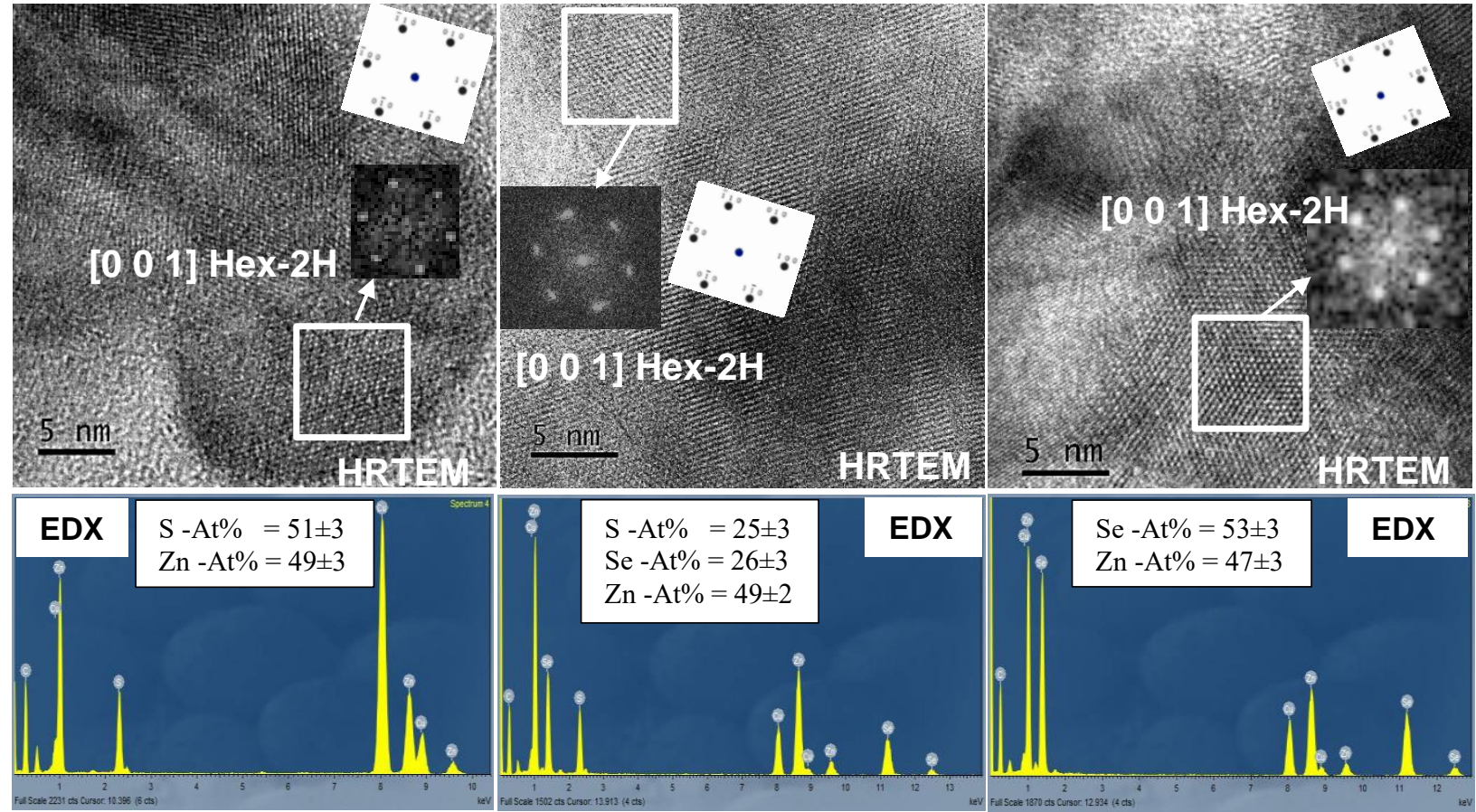

Figure 5. Microstructural characterization (SEM, TEM, EDP, HRTEM and EDX) of (a) ZnS, (b) $\mathrm{ZnS}_{0.5} \mathrm{Se}_{0.5}$ and (c) ZnSe samples milled for 60 min after ignition. Small nanodomains oriented along the $\left[\begin{array}{lll}0 & 0 & 1\end{array}\right]_{2 \mathrm{H}}$ zone axis are white marked and the corresponding FFT and simulated EDP are inset in the HRTEM images. 
TEM microscopes, finding similar results. The average values shown in the EDX spectra presented for the three samples in Figure 5 were in agreement with the expected composition and the atomic ratio in the starting Zn/S/Se mixtures.

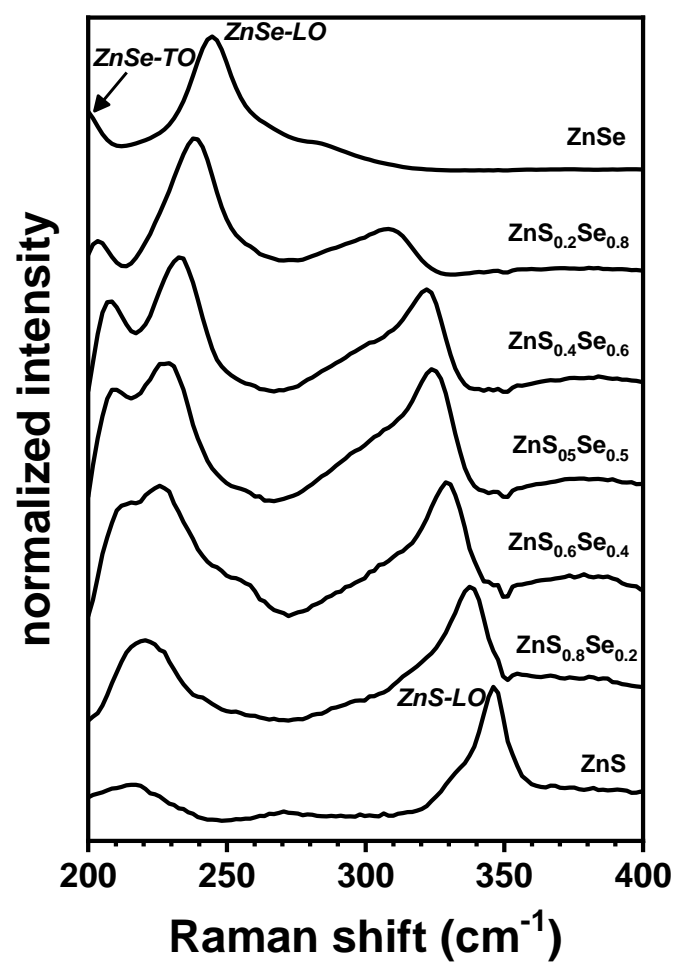

Figure 6. Raman spectra of the different $\mathrm{ZnS}_{\mathrm{x}} \mathrm{Se}_{1-\mathrm{x}}$ samples obtained by MSR.

Figure 6 displays the Raman spectra of the different samples, in which the composition-dependent Raman scattering is clearly observed. The Raman spectrum of the $\mathrm{ZnS}$ sample is dominated in the 200$400 \mathrm{~cm}^{-1}$ region by a main peak located at $\sim 346 \mathrm{~cm}^{-1}$ that corresponds to longitudinal optical (LO) modes in both wurtzite and zinc blende structures ${ }^{61}$. The ZnSe spectrum in Figure 6 is characterized by longitudinal optical (LO) and transverse optical (TO) modes at $\sim 244.5$ and $200 \mathrm{~cm}^{-1}$, respectively ${ }^{62}$. For the $\mathrm{ZnS}_{\mathrm{x}} \mathrm{Se}_{1-\mathrm{x}}$ samples containing $\mathrm{S}$ and Se, the Raman spectra present both ZnS- and ZnSe-like optical modes. Moreover, a shift in the optical phonon frequencies was observed depending on the stoichiometry of the solid solution. As the $\mathrm{S}$ content decreases (or the Se content increases), the $\mathrm{ZnS}$-like LO mode reduces continuously its frequency, while the $\mathrm{ZnSe}$ like LO mode shifts to higher frequencies. However, the ZnSe-like TO mode shifts to lower frequencies, which causes both ZnSe-like modes to increasingly overlap as the $\mathrm{S}$ content increases in the solid solution. Note that the relative intensity of the $\mathrm{ZnS}$ - and ZnSe-like modes correlates well with the stoichiometry of the solid solution. Similar results have been found in the bibliography for $\mathrm{ZnS}_{\mathrm{x}} \mathrm{Se}_{1-\mathrm{x}}$ obtained by evaporation methods ${ }^{23,27,29}$ and confirms that the MSR process allows obtaining homogeneous $\mathrm{ZnS}_{\mathrm{x}} \mathrm{Se}_{1-\mathrm{x}}$ solid solutions.
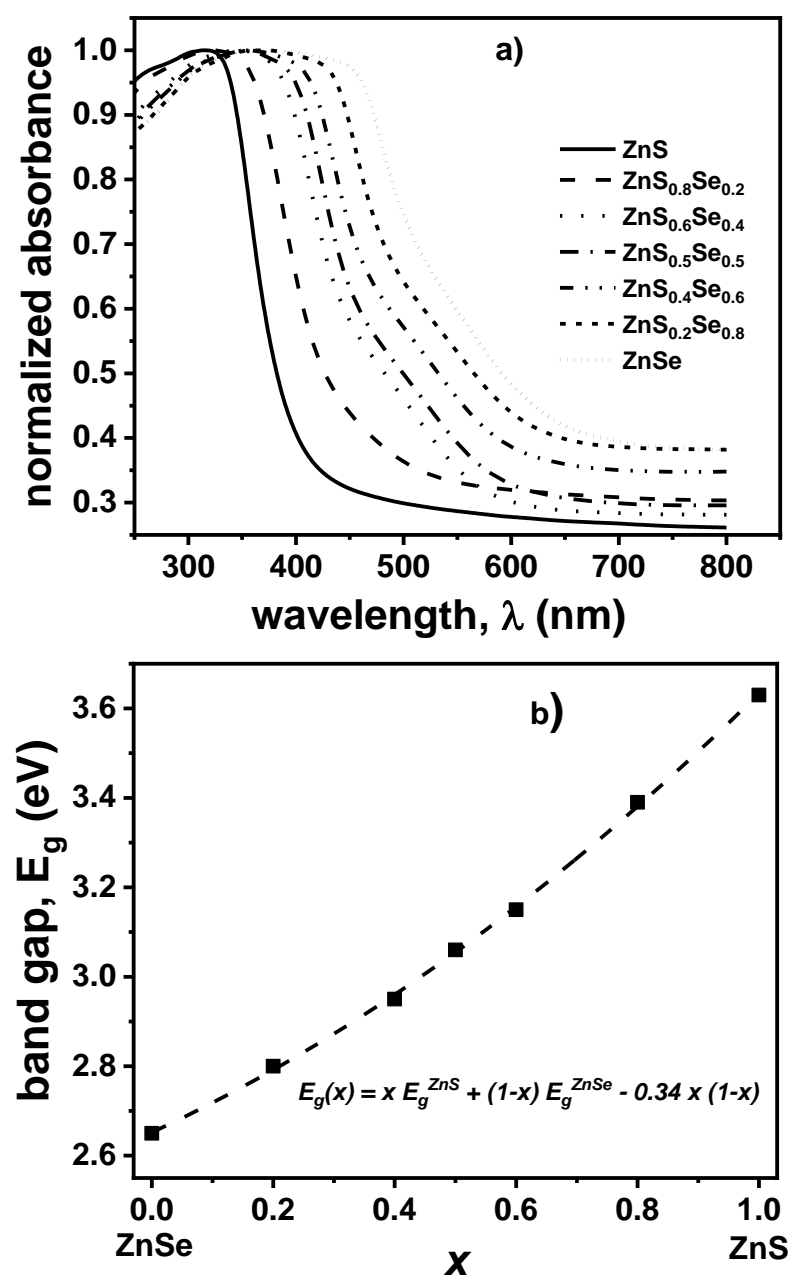

Figure 7. (a) DRS spectra and (b) variation of $E_{g}$ as a function of the stoichiometry of the $\mathrm{ZnS}_{\mathrm{x}} \mathrm{Se}_{1-\mathrm{x}}$ solid solution obtained by MSR.

Figure 7a shows the DRS spectra of the different $\mathrm{ZnS}_{\mathrm{x}} \mathrm{Se}_{1-\mathrm{x}}$ samples in the $250-800 \mathrm{~nm}$ range. It is clearly visible that the absorption edge presents a continuous redshift (towards longer wavelengths) with increase Se content, which implies a decrease in $E_{g}$ as observed in Figure $7 \mathrm{~b}$. The $\mathrm{E}_{\mathrm{g}}$ values for $\mathrm{ZnS}$ and $\mathrm{ZnSe}$ samples coincide with the experimental and 

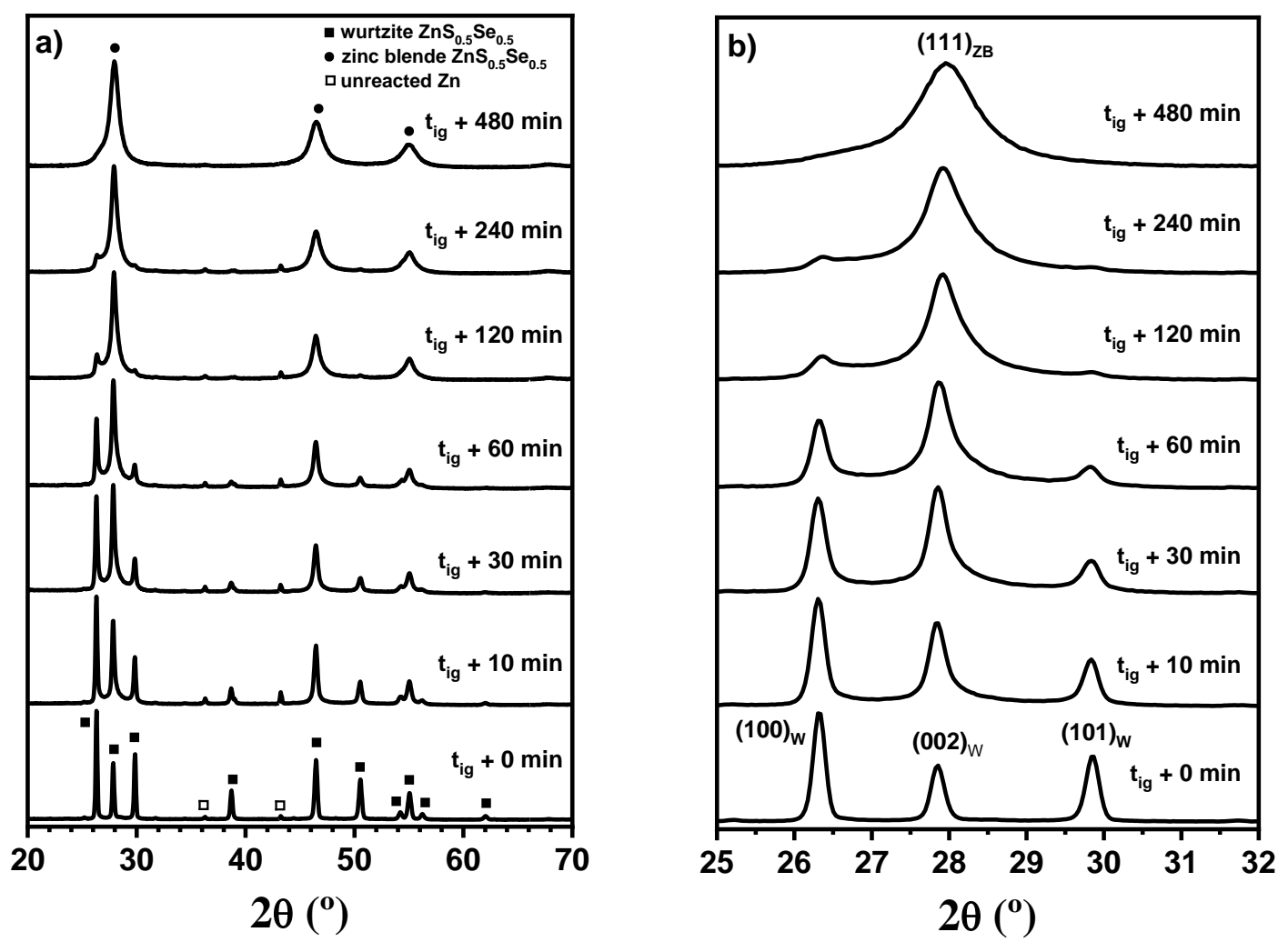

Figure 8. (a) XRD patterns of the $\mathrm{Zn} / \mathrm{S} / \mathrm{Se}$ mixture corresponding to $\mathrm{ZnS}_{0.5} \mathrm{Se}_{0.5}$ subjected at increasing milling times after ignition. (b) XRD patterns of the same samples in the $25^{\circ}-32^{\circ} 2 \theta$ region where the (100), (ooz) and (101) reflections of the wurtzite phase and the (111) reflection of the zinc blende phase are observed.

theoretical values for bulk $\mathrm{ZnS}$ and $\mathrm{ZnSe}{ }^{16}$. Figure $7 \mathrm{~b}$ shows as it is possible to tune $\mathrm{E}_{\mathrm{g}}$ in the $\mathrm{ZnS}-\mathrm{ZnSe}$ system by adjusting the stoichiometry of the $\mathrm{ZnS}_{\mathrm{x}} \mathrm{Se}_{1-\mathrm{x}}$ solid solution that it is accurately controlled by the $\mathrm{Zn} / \mathrm{S} / \mathrm{Se}$ atomic ratio in the starting mixture submitted to milling. The evolution of $\mathrm{E}_{\mathrm{g}}$ with the composition value $x$ in the solid solution was not strictly linear, as frequently observed in the bibliography, and a bowing parameter $b$ of $0.34 \mathrm{eV}$ was obtained. This low value suggests the absence of important compositional fluctuations, as well as short-range order in the solid solution ${ }^{25}$, confirming again a homogeneous distribution of $\mathrm{S}$ and Se in the crystal structure.

\section{Effects of the post-ignition milling time on the crystal structure and the optical properties.}

In this second set of milling experiments, the influence of the milling time on the structure and microstructure of the $\mathrm{ZnS}_{\mathrm{x}} \mathrm{Se}_{1-\mathrm{x}}$ solid solution, and how the optical properties were modified, was studied. The $\mathrm{Zn} / \mathrm{S} / \mathrm{Se}$ powder mixture with atomic ratios according to the $\mathrm{ZnS}_{0.5} \mathrm{Se}_{0.5}$ stoichiometry was chosen as a model sample. Figure 8 shows the XRD patterns for these samples subjected to increasing milling times after ignition (post-ignition milling time). The first experiment corresponds exactly to a milling time equivalent to $t_{i g}$, i.e., the milling process was stopped exactly at ignition with no further milling. The others experiments correspond to samples, for which the milling was prolonged after ignition for 10, 30, 60, 120, 240 and 480 min, respectively. Figure 8 clearly shows how the $\mathrm{ZnS}_{0.5} \mathrm{Se}_{0.5}$ solid solution formed immediately after ignition was obtained practically only with the wurtzite structure, as illustrated in Figure 9, where the results of the quantification by Rietveld (Figure S2) are presented. It is well known that extremely high temperatures are reached locally at ignition, which could favor the formation of the hightemperature structure. As heat losses between the milling media and the environment are important in milling processes, a quench-like phenomenon could have occurred and the wurtzite structure was stabilized at room temperature once the milling was stopped.

By extending the post-ignition milling time, the wurtzite structure was continuously transformed into the zinc blende structure and the full transformation 
TABLE 2. Lattice parameters, crystalline domain size (D) and lattice strain (e) of the wurtzite and zinc blende structures present in the $\mathrm{ZnS}_{0.5} \mathrm{Se}_{0.5}$ sample obtained by MSR as a function of the post-ignition milling time.

$\begin{array}{ccccccccc}\begin{array}{c}\text { Post-ignition } \\ \text { milling time } \\ (\mathrm{min})\end{array} & a(\AA) & c(\AA) & D(\mathrm{~nm}) & e \times 10^{-3}(\%) & a(\AA) & D(\mathrm{~nm}) & e \times 10^{-3}(\%) \\ \text { o } & 3.9079 & 6.4048 & 55.3 & 0.29 & 5.5212 & 58.3 & 0.30 \\ 10 & 3.9089 & 6.4061 & 46.1 & 0.37 & 5.5285 & 37.9 & 0.41 \\ 30 & 3.9045 & 6.4043 & 30.0 & 0.52 & 5.5291 & 40.0 & 0.42 \\ 60 & 3.9090 & 6.4081 & 16.8 & 0.89 & 5.5343 & 38.5 & 0.43 \\ 120 & 3.9011 & 6.4220 & 17.3 & 0.86 & 5.5335 & 17.9 & 0.84 \\ 240 & 3.8790 & 6.4430 & 7.6 & 1.94 & 5.5306 & 11.5 & 1.29 \\ 480 & 3.8822 & 6.4448 & 6.9 & 2.27 & 5.5382 & 8.9 & 1.65\end{array}$

was achieved practically after 480 min (Figures 8 and 9). As the stoichiometry was always the same in this set of experiments, no significant XRD peak shift was detected. Only the phase transformation was observed, without modification of the chemical composition of the solid solution. This fact was confirmed by the constancy of the lattice parameters determined for both structures with milling time (Table 2). Note how the XRD peak broadening was increased with milling time as a result of the expected decrease and increase in particle size and structural defects, respectively (Table 2). Also note that a similar trend was observed for all samples in the $\mathrm{ZnS}_{x} \mathrm{Se}_{1-\mathrm{x}}$ solid solution. Although at $t_{i g}$ the amount of wurtzite phase formed was dependent on the $x$ value, if the milling was prolonged, the wurtzite phase was continuously transformed into zinc blende.

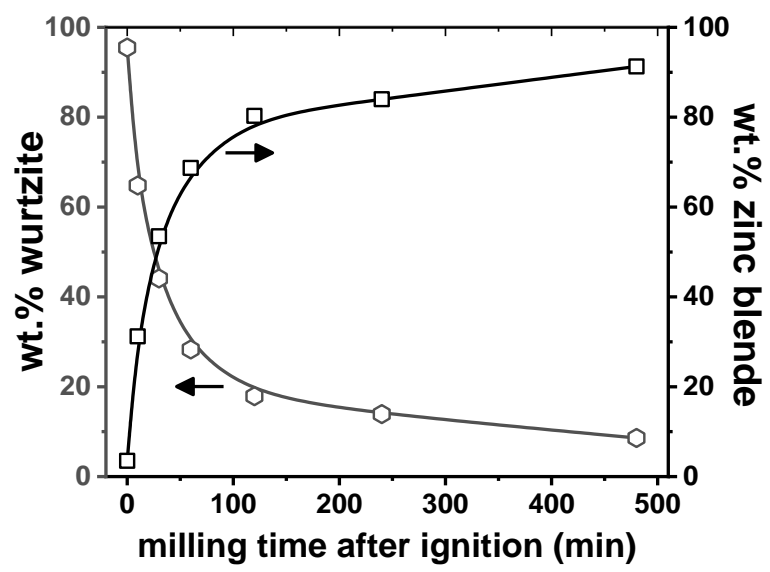

Figure 9. Quantification of the zinc blende and wurtzite phases present in the ZnSo.5Seo.5 sample subjected at increasing post-ignition milling time by Rietveld refinement of the XRD patterns in Figure 8.
Figure 10 exhibits representative SEM/TEM results for the samples stopped at ignition $\left(\mathrm{ZnS}_{0.5} \mathrm{Se}_{0.5} \mathrm{-o}\right)$ and milled for $480 \mathrm{~min}$ after ignition $\left(\mathrm{ZnS}_{0.5} \mathrm{Se}_{0.5}-480\right)$. The difference between both samples can be clearly seen in the SEM micrographs. Well-defined hexagonal prisms were formed in the sample $\mathrm{ZnS}_{0.5} \mathrm{Se}_{0.5}{ }^{-0}$ with sizes ranging between $0.2-1 \mu \mathrm{m}$ in the base and $0.5^{-2}$ $\mu \mathrm{m}$ in height. Spherical particles (0.2-1 $\mu \mathrm{m}$ of diameter) are also observed, and they are formed in turn by smaller particles, as can be seen in the enlargement that is presented in the inset below to the right. Note that this sample was not subjected to milling after ignition and the morphology observed was the result of the self-sustaining reaction. On the other hand, the sample $\mathrm{ZnS}_{0.5} \mathrm{Se}_{0.5}-48 \mathrm{o}$, presents the typical appearance of powder samples obtained by mechanical milling, formed by an agglomeration of small rounded particles.

The differences between samples were also observed in the TEM images and EDP. The $\mathrm{ZnS}_{0.5} \mathrm{Se}_{0.5^{-}}$ 480 sample shows ring-EDPs with diffuse scattering (corresponding (h, k, l) are marked), which implies that the sample was nanocrystalline. However, in the $\mathrm{ZnS}_{0.5} \mathrm{Se}_{0.5}$-o sample some microcrystallites were detected with characteristic spot-EDPs. A representative one is presented in the up-left corner, which is oriented along the $[621]_{2 \mathrm{H}}$ axis. Ring-EDPs were as well found, but formed in this case by many diffraction spots (indexed in the EDP), in agreement with larger crystalline domains. The HRTEM micrograph show a large crystalline domain oriented along the $\left[\begin{array}{lll}0 & 0 & 1\end{array}\right]_{2 \mathrm{H}}$ zone axis of the hexagonal structure and the corresponding FFT and simulated EDP are inset (Fig.10a). Taking into account that these two samples are the ends of the experiment analyzing the influence of the post-ignition milling time, it is worth to compare them with the sample $\mathrm{ZnS}_{0.5} \mathrm{Se}_{0.5}$ after $60 \mathrm{~min}$ of 
a) $\mathrm{ZnS}_{0.5} \mathrm{Se}_{0.5}-\mathrm{0}$
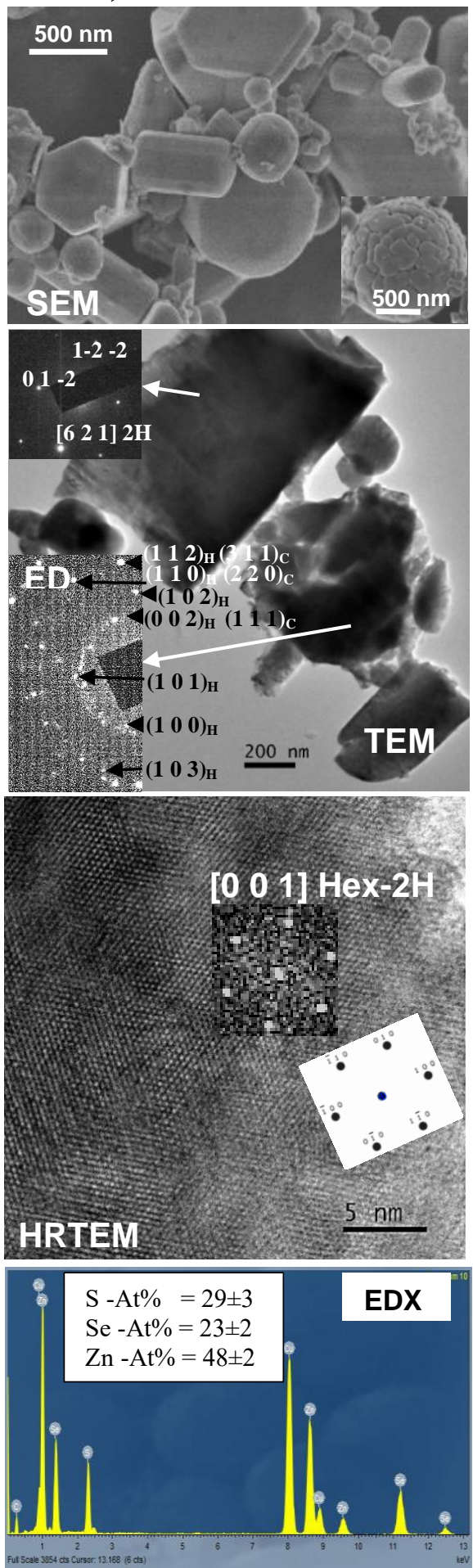

b) $\mathrm{ZnS}_{0.5} \mathrm{Se}_{0.5}-480$
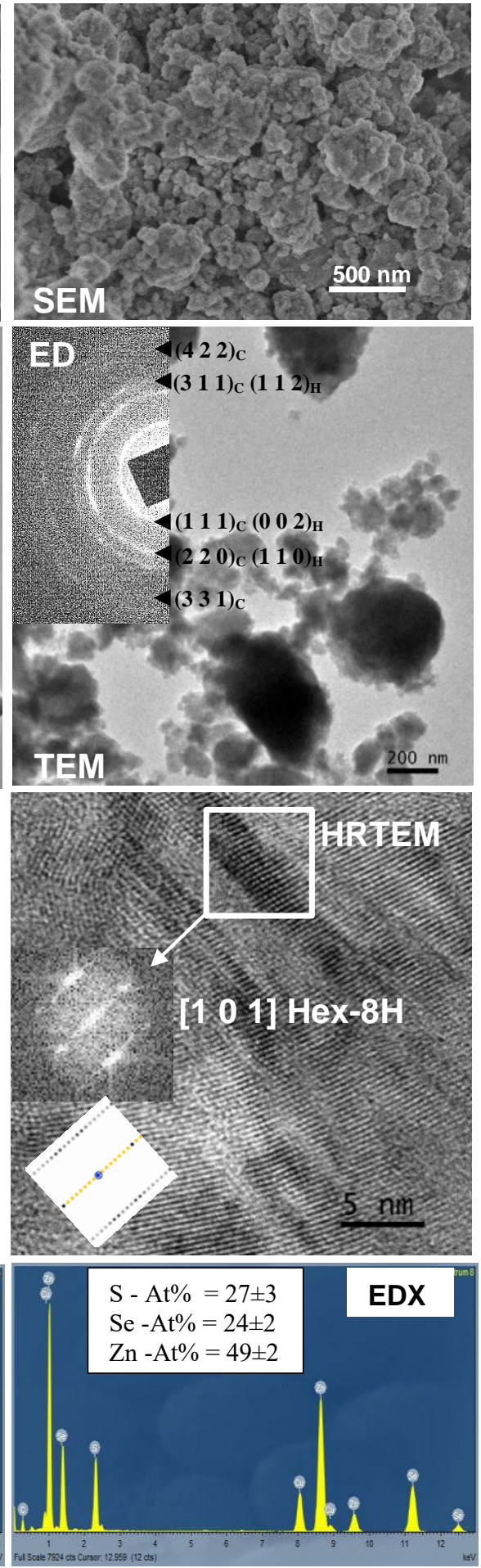

FIGURE 10. Microstructural characterization (SEM, TEM, ED, HRTEM and EDX) of $\mathrm{ZnS}_{0.5} \mathrm{Se}_{0.5}$ samples, just (a) after ignition and (b) after 480 min of milling Small nanodomains oriented along the $\left[\begin{array}{lll}0 & 0\end{array}\right]_{2 \mathrm{H}}$ and $\left[\begin{array}{lll}1 & 0 & 1\end{array}\right]_{8 \mathrm{H}}$ zone axis are white marked and the corresponding FFT and simulated EDP are inset in the HRTEM images. 
milling presented in Figure $5 \mathrm{~b}$. The features of the sample, as expected, are more similar to that found for $\mathrm{ZnS}_{0.5} \mathrm{Se}_{0.5}-480$, although with larger particle size due to the shorter post-ignition milling time. The chemical analysis of both samples was carried out by EDX and two representative spectra obtained in the TEM microscope are depicted at the bottom of Figure 10. The values are near of the atomic ratio in the starting $\mathrm{Zn} / \mathrm{S} / \mathrm{Se}$ mixture and no significant variations were observed during the post-ignition milling process.

The HRTEM analysis of the $\mathrm{ZnS}_{0.5} \mathrm{Se}_{0.5}-480$ sample showed the existence of some regions with the $8 \mathrm{H}$ hexagonal polytype structure. A small crystalline nanodomain (square white marked) oriented along the $\left[\begin{array}{lll}1 & 0 & 1\end{array}\right]_{8 \mathrm{H}}$ is presented in Figure $10 \mathrm{~b}$ and the FFT/simulated EDP are inset. The $8 \mathrm{H}$ polytype has already been described in ZnSe using HRTEM by Paszkowicz ${ }^{63}$. There are also some other authors ${ }^{64,65}$ that described twins or defects in ZnSe, however, the contrast in the HRTEM images they presented was very similar to that found for the polytypes. Note that the XRD patterns of the $8 \mathrm{H}$-hexagonal and cubic zinc blende structures are similar and its differentiation is a difficult task, especially in nanocrystalline samples.

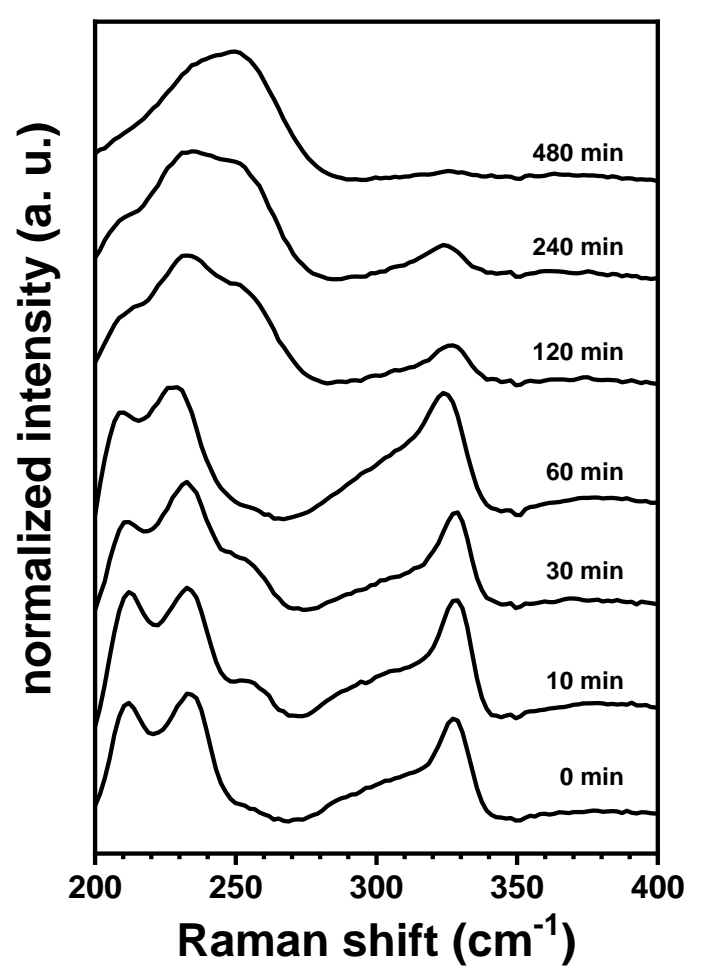

Figure 11. Raman spectra of the $\mathrm{ZnS}_{0.5} \mathrm{Se}_{0.5}$ sample obtained by MSR at increasing post-ignition milling time.
Figure 11 shows the Raman spectra of the $\mathrm{ZnS}_{0.5} \mathrm{Se}_{0.5}$ sample at increasing milling time. Up to 60 min of post-ignition milling time, the Raman spectra did not exhibit great differences, only a small redshift was observed in all ZnS- and ZnSe-like optical modes. From $120 \mathrm{~min}$, the intensity of the ZnS-like LO mode began to decrease significantly and the ZnSe-like TO and LO modes broadened and overlapped with each other and with a third peak appearing at $\sim 256 \mathrm{~cm}^{-1}$.

After 480 min of post-ignition milling, only one broad peak extending from 200 to $290 \mathrm{~cm}^{-1}$ was observed in the Raman spectrum. The Raman peak at $256 \mathrm{~cm}^{-1}$ observed in some samples may be associated with lattice defects (stacking faults) in the crystal structure ${ }^{66}$ or with unresolved ZnS-like TO modes ${ }^{67}$. However, the fact that the ZnS-like TO modes has never been observed in $\mathrm{ZnS}_{x} \mathrm{Se}_{1-x}$ thin films and that the Raman band increased appreciably with milling time suggested that this peak was a defect related mode. Note that during milling not only the phase transformation from wurtzite to zinc blende took place, but also the decrease in particle size and the increase in structural defects and lattice strains, as shown in Table 2. In this sense, it has been reported that tensile and compressive strains may cause in Raman bands redshifts and blueshifts, respectively ${ }^{68}$. Moreover, the phonon confinement effect in nanostructured materials results in asymmetric broadening and also redshift of the Raman bands ${ }^{69,70}$. The presence of a high concentration of structural defects also broaden the Raman lines due to the consequent breakdown of the selection rule for Raman scattering. Figure 11 suggests that the intensity of the ZnS-like modes is more affected than the ZnSe-like modes by the defects induced by milling under the excitation energy used in this work.

Figure 12 shows the DRS spectra of the $\mathrm{ZnS}_{0.5} \mathrm{Se}_{0.5}$ sample at increasing post-ignition milling time. The differences between the spectra are small, since the chemical composition of the solid solution, which was the main factor that determined the optical properties, was always the same. The $\mathrm{E}_{\mathrm{g}}$ values determined for the different samples were similar, within a narrow energy range of 3.00-3.10 eV. As indicated above, for this set of experiments, milling induced primarily the phase transformation of wurtzite into zinc blende and the decrease in particle size. Bearing in mind that in $\mathrm{ZnS}$ the wurtzite structure has a slightly higher $E_{g}$ than zinc blende, and that the decrease in the crystalline domain size, with values in the nanometer range (Table 2), can also induce an increase in $\mathrm{Eg}^{71}$, the small differences observed in this set of samples with the post-ignition milling time may be the result of these two effects. 


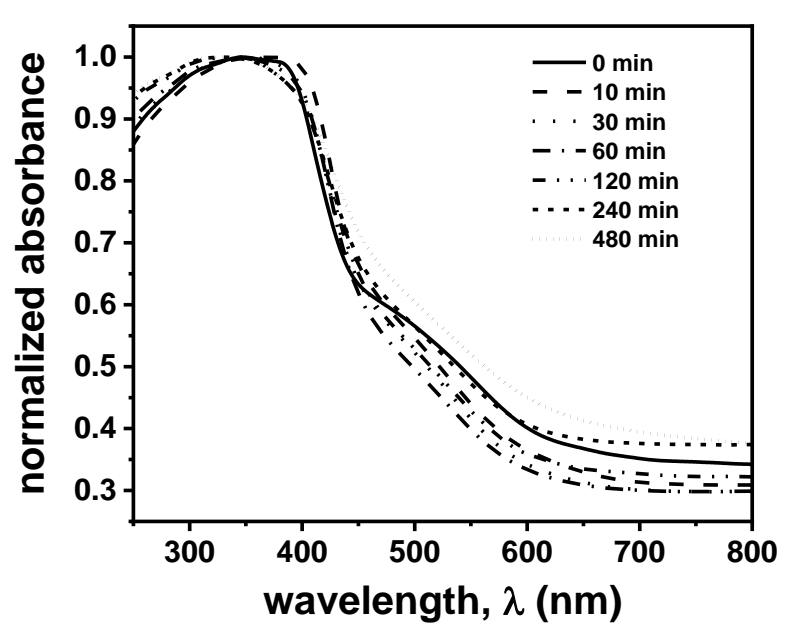

Figure 12. DRS spectra of the $\mathrm{ZnS}_{0.5} \mathrm{Se}_{0.5}$ sample obtained by MSR at increasing post-ignition milling time.

\section{CONCLUSIONS}

1. The high exothermic character of the formation reaction of $\mathrm{ZnS}$ and $\mathrm{ZnSe}$ allowed the synthesis of the complete $\mathrm{ZnS}_{\mathrm{x}} \mathrm{Se}_{1-\mathrm{x}}$ solid solution by the mechanochemical process denoted as mechanicallyinduced self-sustaining reaction (MSR). An excellent control of the chemical stoichiometry was successfully obtained by adjusting the starting $\mathrm{Zn} / \mathrm{S} / \mathrm{Se}$ atomic ratio that was subjected to milling.

2. The ignition time of the MSR process was composition dependent and gradually reduced with the Se content in the solid solution. Under the milling conditions employed, it ranged from 9 to $77 \mathrm{~min}$.

3. A mixture of the wurtzite and zinc blende structures was obtained after the MSR process. The zinc blende proportion increased as the Se content increased in the solid solution. Prolonging milling after ignition induced the wurtzite-to-zinc blende phase transformation. The lattice parameters evolution of both structures with the stoichiometry of the solid solution were perfectly linear, following the Vegard's law.

4. SEM/TEM characterization showed that the MSR process allows obtaining homogeneous $\mathrm{ZnS}_{\mathrm{x}} \mathrm{Se}_{1-\mathrm{x}}$ solid solutions in terms of composition and microstructure. The HRTEM revealed the nanocrystalline character of the samples subjected to milling after ignition and the formation of the $8 \mathrm{H}$ polytype hexagonal structure for prolonged milling time. The SEM/TEM characterization also showed the great difference in the $\mathrm{ZnS}_{0.5} \mathrm{Se}_{0.5}$ sample obtained when the milling was stopped just at ignition in terms of shape and size of the particles if compared with the samples with a post-ignition milling time.
5. Raman scattering and UV-Vis absorbance spectra of the $\mathrm{ZnS}_{\mathrm{x}} \mathrm{Se}_{1-\mathrm{x}}$ solid solution also revealed a composition dependent behavior. The $E_{g}$ values determined from the UV-Vis spectra of the solid solution demonstrated that $\mathrm{E}_{\mathrm{g}}$ can be perfectly modulated between the extreme values of the end-members. The dependence of $\mathrm{E}_{\mathrm{g}}$ with the stoichiometry was not perfectly linear and a small bowing parameter of 0.34 was obtained according to the formation of a homogeneous solid solution.

\section{ASSOCIATED CONTENT}

Further Rietveld results from the XRD patterns in Figures 2 and 8, from which lattice parameters and phase quantification were determined. This material is available free of charge via the Internet at http://pubs.acs.org.

\section{AUTHOR INFORMATION}

\section{Corresponding Author}

*E-mail: fgotor@cica.es

\section{Author Contributions}

The manuscript was written through contributions of all authors. All authors have given approval to the final version of the manuscript and contributed equally.

\section{Funding Sources}

This work was supported by the Spanish government under Grant no. MAT2014-52407-R financed in part by the European Regional Development Fund and through the Ramón y Cajal Program RYC-2013-12437.

\section{Notes}

The authors declare no competing financial interest.

\section{REFERENCES}

(1) Wang, A.; Shen, H.; Zang, S.; Lin, Q.; Wang, H.; Qian, L.; Niu, J.; Li, L. S. Bright, Efficient, and Color-Stable Violet ZnSe-based Quantum Dot Light-Emitting Diodes. Nanoscale 2015, 7, 2951-2959.

(2) Zhu, D.; Jiang, X.; Zhao, C.; Sun, X.; Zhang, J.; Zhu, J. J. Green Synthesis and Potential Application of Low-Toxic Mn: ZnSe/ZnS Core/Shell Luminescent Nanocrystals. Chem. Commun. 2010, 46, 5226-5228.

(3) La Porta, F. A.; Gracia, L.; Andrés, J.; Sambrano, J. R.; Varela, J. A.; Longo, E. A DFT Study of Structural and Electronic Properties of ZnS Polymorphs and its PressureInduced Phase Transitions. J. Am. Ceram. Soc. 2014, 97, 4011-4018.

(4) Ono, S.; Kikegawa T., Phase Transition of ZnS at High Pressures and Temperatures. Phase Transitions 2018, 91, 9-14.

(5) Zhao, Y.; Zhang, Y.; Zhu, H.; Hadjipanayis, G. C.; Xiao, J. Q. Low-Temperature Synthesis of Hexagonal (Wurtzite) ZnS Nanocrystals. J. Am. Chem. Soc. 2004, 126, 6874-6875.

(6) Acharya, S. A.; Maheshwari, N.; Tatikondewar, L.; Kshirsagar, A.; Kulkarni, S. K. Ethylenediamine-Mediated 
Wurtzite Phase Formation in ZnS. Cryst. Growth Des. 2013, 13, 1369-1376.

(7) Chen, X.; Xu, H.; Xu, N.; Zhao, F.; Lin, W.; Lin, G.; Fu, Y.; Huang, Z.; Wang, H.; Wu, M. Kinetically Controlled Synthesis of Wurtzite ZnS Nanorods through Mild Thermolysis of a Covalent Organic-Inorganic Network. Inorg. Chem. 2003, 42, 3100-3106.

(8) Feigl, C. A.; Barnard, A. S.; Russo, S. P. Size- and Shape-Dependent Phase Transformations in Wurtzite ZnS Nanostructures. Phys. Chem. Chem. Phys. 2012, 14, 98719879 .

(9) Wang, Z.; Daemen, L. L.; Zhao, Y.; Zha, C. S.; Downs, R. T.; Wang, X.; Wang, Z. L.; Hemley, R. J. Morphology-Tuned Wurtzite-type ZnS Nanobelts. Nat. Mater. 2005, 4, 922-927.

(10) Barlow, D. A. Predicting the Temperature for the Solid-Solid Phase Transition in II-VI Semiconductor Alloys. J. Phys. Chem. Solids 2013, 74, 406-409.

(11) Cao, F.; Shi, W.; Zhao, L.; Song, S.; Yang, J.; Lei, Y.; Zhang, H. Hydrothermal Synthesis and High Photocatalytic Activity of $3 \mathrm{D}$ Wurtzite ZnSe Hierarchical Nanostructures. J. Phys. Chem. C 2008, 112, 17095-17101.

(12) Acharya, S.; Sarkar, S.; Pradhan, N. Material Diffusion and Doping of $\mathrm{Mn}$ in Wurtzite ZnSe Nanorods. J. Phys. Chem. C 2013, 117, 6006-6012.

(13) Cozzoli, P. D.; Manna, L.; Curri, M. L.; Kudera, S.; Giannini, C.; Striccoli, M.; Agostiano, A. Shape and Phase Control of Colloidal ZnSe Nanocrystals. Chem. Mater. 2005, 17, 1296-1306.

(14) Yeh, C. Y.; Lu, Z. W.; Froyen, S.; Zunger, A. ZincBlende-Wurtzite Polytypism in Semiconductors. Phys. Rev. B 1992, 46, 10086-10097.

(15) Qteish, A.; Muñoz, A. Stability and Structural Properties of ZnS and ZnSe under High Pressure. Phys. Stat. Sol. B 2001, 223, 417-422.

(16) Trindade, T.; O’Brien, P.; Pickett, N. L. Nanocrystalline Semiconductors: Synthesis, Properties, and Perspectives. Chem. Mater. 2001, 13, 3843-3858.

(17) Janetzko, F.; Jug, K. Miscibility of Zinc Chalcogenides. J. Phys. Chem. A 2004, 108, 5449-5453.

(18) El Haj Hassan, F.; Amrani, B.; Bahsoun, F. Ab Initio Investigations of Zinc Chalcogenides Semiconductor Alloys. Physica B 2007, 391, 363-370.

(19) Homann, T.; Hotje, U.; Binnewies, M.; Börger, A.; Becker, K. D.; Bredow, T. Composition-Dependent Band Gap in ZnSxSe1-x: A Combined Experimental and Theoretical Study. Solid State Sci. 2006, 8, 44-49.

(20) Ebina, A.; Fukunaga, E.; Takahashi, T. Variation with Composition of the Eo and Eo + ?o Gaps in ZnSxSe1-x Alloys. Phys. Rev. B 1974, 10, 2495-2500.

(21) Okuyama, H.; Kishita, Y.; Ishibashi, A. Quaternary Alloy Zn1-xMgxSySe1-y. Phys. Rev. B 1998, 57, 2257-2263.

(22) E1-Shazly, A. A.; E1-Naby, M. M. H.; Kenawy, M. A.; E1-Nahass, M. M.; E1-Shair, H. T.; Ebrahim, A. M. Optical Properties of Ternary $\mathrm{ZnS}_{\mathrm{x}} \mathrm{Se}_{1-\mathrm{x}}$ Polycrystalline Thin Films. Appl. Phys. A 1985, 36, 51-53.

(23) Xu, H.; Liang, Y.; Liu, Z.; Zhang, X.; Hark, S. Synthesis and Optical Properties of Tetrapod-Like ZnSSe Alloy Nanostructures. Adv. Mater. 2008, 20, 3294-3297.
(24) Choi, Y. J.; Kwon, S. J.; Choi, K. J.; Kim, D. W.; Park, J. G. Synthesis and Optical Properties in ZnSxSe1-x Alloy Nanowires. J. Korean Phys. Soc. 2009, 54, 1650-1654.

(25) Bernard, J. E.; Zunger, A. Electronic Structure of ZnS, ZnSe, ZnTe, and their Pseudobinary Alloys. Phys. Rev. B 1987, 36, 3199-3228.

(26) Wang, M.; Fei, G. T.; Zhang, Y. G.; Kong, M. G.; Zhang, L. D. Tunable and Predetermined Bandgap Emissions in Alloyed ZnSxSe1-x Nanowires. Adv. Mater. 2007, 19, 4491-4494.

(27) Chuo, H. X.; Wang, T. Y.; Zhang, W. G. Optical Properties of ZnSxSe1-x Alloy Nanostructures and their Photodetectors. J. Alloys Compd. 2014, 6o6, 231-235.

(28) Liang, Y.; Xu, H.; Hark, S. Epitaxial Growth and Composition-Dependent Optical Properties of Vertically Aligned ZnS1-xSex Alloy Nanowire Arrays. Cryst. Growth Des. 2010, 10, 4206-4210.

(29) Lu, J.; Liu, H.; Sun, C.; Zheng, M.; Nripan, M.; Chen, G. S.; Subodh, G. M.; Zhang, X.; Sow, C. H. Optical and Electrical Applications of ZnSxSe1-x NanowiresNetwork with Uniform and Controllable Stoichiometry. Nanoscale 2012, 4, 976-981.

(30) Park, S.; Kim, H.; Jin, C.; Lee, C. Synthesis, Structure, and Photoluminescence Properties of ZnSSe Alloy Nanorods. Curr. Appl. Phys. 2012, 12, 499-503.

(31) Sadekar, H. K.; Ghule, A. V.; Sharma, R. Bandgap Engineering by Substitution of $\mathrm{S}$ by Se in Nanostructured ZnS1-xSex Thin Films Grown by Soft Chemical Route for Nontoxic Optoelectronic Device Applications. J. Alloys Compd. 2011, 509, 5525-5531.

(32) Balaz, P.; Achimovicova, M.; Balaz, M.; Billik, P.; Cherkezova-Zheleva, Z.; Criado, J. M.; Delogu, F.; Dutkova, E.; Gaffet, E.; Gotor, F. J.; Kumar, R.; Mitov, I.; Rojac, T.; Senna, M.; Streletskii, A.; Wieczorek-Ciurowa, K. Hallmarks of Mechanochemistry: From Nanoparticles to Technology. Chem. Soc. Rev. 2103, 42, 7571-7637.

(33) Tschaharov, C. G.; Gospodinov, G. G.; Bontschev, Z. Über den Mechanismus der mechanochemischen Synthese anorganischer Verbindungen. J. Solid State Chem. 1982, 41, 244-252.

(34) Chakurov, Chr.; Rusanov, V.; Koichev, J. The Effect of Inert Additives on the Explosive Mechanochemical Synthesis of some Metal Chalcogenides. J. Solid State Chem. $1987,71,522-529$.

(35) Bakhshai, A.; Soika, V.; Susol, M. A.; Takacs, L. Mechanochemical Reactions in the Sn-Zn-S System: Further Studies. J. Solid State Chem. 2000, 153, 371-380.

(36) de Lima, J. C.; dos Santos, V. H. F.; Grandi, T. A. Structural Study of the Zn-Se System by Ball Milling Technique. Nanostruct. Mater. 1999, 11, 51-57.

(37) Rafea, M. A. Preparation and Characterization of ZnSe Nanoparticles by Mechanochemical Process. J. Mater. Sci.: Mater. Electron. 2007, 18, 415-420.

(38) Li, J.; Wang, M.; Huo, X.; Yao, X. Preparation and Optical Properties of Dispersible ZnSe Nanocrystals Synthesized by High Energy Ball Milling. Ceram. Int. 20o8, 34, 1077-1080.

(39) Che, J.; Yao, X.; Wan, X.; Jiang, H. Q.; Wang, M. Q. Synthesis of ZnSe Nanocrystalline Powders by Mechanochemical Reaction. J. Electroceram. 2008, 21, 729-732. 
(40) Patra, S.; Satpati, B.; Pradhan, S. K. Microstructure Characterization of Mechanically Synthesized ZnS Quantum Dots. J. Appl. Phys. 2009, 106, 034313.

(41) Achimovičová, M.; Baláž, P.; Ohtani, T.; Kostova, N.; Tyuliev, G.; Feldhoff, A.; Šepelák, V. Characterization of Mechanochemically Synthesized ZnSe in a Laboratory and an Industrial Mill. Solid State Ionics 2011, 192, 632-637.

(42) Faita, F. L.; Ersching, K.; Poffo, C. M.; Benetti, L. C.; Trichês, D. M.; Souza, S. M.; Viegas, A. D. C.; de Lima, J. C. Structural, Thermal, Magnetic and Optical Characterization of Undoped Nanocrystalline ZnS Prepared by Solid State Reaction. J. Alloys Compd. 2014, 590, 176-183.

(43) Ohtani, T.; Kusano, Y.; Ishimaru, K.; Morimoto, T.; Togano, A.; Yoshioka, T. Pre-Milling Effects on SelfPropagating Reactions in Mechanochemical Synthesis of CdSe and ZnSe. Chem. Lett. 2015, 44, 1234-1236.

(44) Gotor, F. J.; Achimovicova, M.; Real, C.; Balaz, P. Influence of the Milling Parameters on the Mechanical Work Intensity in Planetary Mills. Powder Technol. 2013, 233, 1-7.

(45) Dhara, A.; Sain, S.; Das, S.; Pradhan, S. K. Microstructure, Optical and Electrical Characterizations of $\mathrm{Mn}$ doped ZnS Nanocrystals Synthesized by Mechanical Alloying. Mater. Res. Bull. 2018, 97, 169-175.

(46) Tsuzuki, T.; McCormick, P. G. Mechanochemical Synthesis of Metal Sulphide Nanoparticles. Nanostruct. Mater. 1999, 12, 75-78.

(47) Dutková, E.; Baláž, P.; Pourghahramani, P.; Velumani, S.; Ascencio, J. A.; Kostova, N. G. Properties of Mechanochemically Synthesized ZnS Nanoparticles. J. Nanosci. Nanotechnol. 2009, 9, 6600-6605.

(48) Setoudeh, N.; Welham, N. J. Metallothermic Reduction of Zinc Sulfide Induced by Ball Milling. J. Mater. Sci. 2017, 52, 6388-6400.

(49) Nasar, A.; Shamsuddin, M. Investigations of the Thermodynamic Properties of Zinc Chalcogenides. Thermochim. Acta 1992, 205, 157-169.

(50) Deidda, C.; Delogu, F.; Maglia, F.; AnselmiTamburini, U.; Cocco, G. Mechanical Processing and SelfSustaining High-Temperature Synthesis of TiC Powders. Mater. Sci. Eng. A 2004, 375, 800-803.

(51) Trapp, J.; Kieback, B. Solid-State Reactions during High-Energy Milling of Mixed Powders. Acta Mater. 2013, 61, 310-320.

(52) Chicardi, E.; Gotor, F. J.; Alcalá, M. D.; Córdoba, J. M. Influence of Milling Parameters on the Solid-Gas Synthesis of TiCxN1-x by Mechanically Induced Self-Sustaining Reaction. Powder Technol. 2017, 319, 12-18.

(53) Damm, C.; Armstrong; P.; Roßkopf, C.; Romeis, S.; Peukert, W. Mechanically Induced Phase Transformation of Zinc Sulfide. Particuology 2015, 18, 1-10.

(54) Tiwary, C. S.; Saha, S.; Kumbhakar, P.; Chattopadhyay, K. Observation of Combined Effect of Temperature and Pressure on Cubic to Hexagonal Phase Transformation in ZnS at the Nanoscale. Cryst. Growth Des. 2014, 14, $4240-4246$.
(55) Rodriguez-Carvajal, J. Recent Advances in Magnetic Structure Determination by Neutron Powder Diffraction, Physica B 1993, 192, 55-69.

(56) Binnewies, M.; Milke, E. Thermochemical Data of Elements and Compounds; Wiley-VCH: Germany, 1999.

(57) Takacs, L. Self-Sustaining Reactions Induced by Ball Milling. Progr. Mater. Sci. 2002, 47, 355-414.

(58) Kosmac, T.; Courtney, T. H. Milling and Mechanical Alloying of Inorganic Nonmetallic. J. Mater. Res. 1992, 7, 1519-1525.

(59) Zhao, Y. H.; Zhu, Y. T.; Liu, T. Mechanism of Solid-State Amorphization of Se Induced by Mechanical Milling. J. Appl. Phys. 2004, 95, 7674-7680.

(6o) Chen, Y.; Liu, Y.; Chu, M.; Wang, L. Phase Diagrams and Thermodynamic Descriptions for the Bi-Se and Zn-Se Binary Systems. J. Alloys Compd. 2014, 617, 423-428.

(61) Cheng, Y. C.; Jin, C. Q.; Gao, F.; Wu, X. L.; Zhong, W.; Li, S. H.; Chu, P. K. Raman Scattering Study of Zinc Blende and Wurtzite ZnS. J. Appl. Phys. 2009, 106, 123505.

(62) Lu, G.; An, H.; Chen, Y.; Huang, J.; Zhang, H.; Xiang, B.; Zhao, Q.; Yu, D.; Du, W. Temperature Dependence of Raman Scattering of ZnSe Nanoparticle Grown through Vapor Phase. J. Cryst. Growth 2005, 274, 530-535.

(63) Paszkowicz, W.; Dluzewski, P.; Spolnik, Z. M.; Firszt, F.; Meczynska, H. Formation of $4 \mathrm{H}$ and $8 \mathrm{H}$ Polytypes in Bulk Zn1-xMgxSe Crystals. J. Alloys Compd. 1999, 286, 224-235.

(64) Li, Q.; Gong, X.; Wang, C.; Wang, J.; Ip, K.; Hark, S. Size-Dependent Periodically Twinned ZnSe Nanowires. Adv. Mater. 2004, 16, 1436-1440.

(65) Wang, Y. Q.; Philipose, U.; Ruda, H.; Kavanagh, K. L. Planar Defects and Phase Transformation in ZnSe Nanosaws. J. Mater. Sci.: Mater. Electron. 2006, 17, 10651070.

(66) Jabri, S.; Amiri, G.; Hassani, S.; Lusson, A.; Sallet, V.; Meftah, A.; Galtier, P.; Oueslati, M. Zinc Blende-Oxide Phase Transformation upon Oxygen Annealing of ZnSe Shell in ZnO-ZnSe Core-Shell Nanowires. Appl. Phys. Lett. 2017, 110, 101601.

(67) Adu, K. W.; Xiong, Q.; Gutierrez, H. R.; Chen, G.; Eklund, P. C. Raman Scattering as a Probe of Phonon Confinement and Surface Optical Modes in Semiconducting Nanowires. Appl. Phys. A 2006, 85, 287-297.

(68) Kim, J. H.; Rho, H.; Kim, J.; Choi, Y-J.; Park, J-G. Raman Spectroscopy of ZnS Nanostructures. J. Raman Spectrosc. 2012, 43, 906-910.

(69) Arora, A. K.; Rajalakshmi, M.; Ravindran, T. R.; Sivasubramanian, V. Raman Spectroscopy of Optical Phonon Confinement in Nanostructured Materials. J. Raman Spectrosc. 2007, 38, 604-617.

(70) Zhou, X.; Zeng, X.; Yan, X.; Xia, W.; Zhou, Y.; Shen, X. Shape- and Phase-Controlled ZnS Nanostructures and their Optical Properties. Mater. Res. Bull. 2014, 59, 2531 .

(71) Bera, D.; Qian, L.; Tseng, T. K.; Holloway, P. H. Quantum Dots and their Multimodal Applications: A Review. Materials 2010, 3, 2260-2345. 